\title{
Adverse Drug Reactions pattern in a tertiary level teaching hospital: A Retrospective Study
}

\author{
Anita Gupta, Anjleen Kaur, Prashant Shukla*, Hema Chhabra \\ Department of Pharmacology, Government Medical College, Patiala, Punjab, INDIA.
}

\begin{abstract}
Objective: The objective of the study was to assess the pattern of adverse drug reactions (ADRs) along with the severity and causality assessment of the ADRs in the local population. Method: This was an observational and retrospective study. A total of 288 adverse drug reactions were reported from 175 patients of the outpatient and inpatient department of various clinical departments of Rajindra Hospital, Government Medical College, Patiala, Punjab. The ADRs were collected duringNovember 2015- August 2016. Results: The mean age of the patients was $43.14( \pm 2.27)$ years. Gender distribution of the patients showed that there were $67(38.28 \%)$ female and $108(61.7 \%)$ male patients indicating male preponderance. Out of 288 ADRs, the majority of ADRs were related to the skin and appendages (26.04\%) closely followed by gastrointestinal disorders (24.3\%). Other ADRs were related to Central nervous system (12.15\%), respiratory system (7.29\%), cardiovascular system $(6.94 \%)$ and others (23.2\%). Using Naranjo's causality assessment scale, there were 9 definite, 131 probable, 136 possible and 12 doubtful/ unlikely causality of the ADRs with the suspected offending drug. Using Hartwig and Siegel scale of severity of ADR, it was found that there were 230 mild $(79.86 \%), 52$ moderate $(18.05 \%)$ and 6 severe $(2.08 \%)$ ADRs. Conclusion: The process of pharmacovigilance is a continuous one so as to detect even the rare ADRs.
\end{abstract}

Key words: Adverse drug reactions (ADRs), Spontaneous reporting, Pharmacovigilance, Naranjo's scale, Hartwig and Siegel scale.

\section{INTRODUCTION}

According to World Health Organization (WHO), an adverse drug reaction (ADR) is defined as "a response to a drug which is noxious and unintended, and which occurs at doses normally used in man for the prophylaxis, diagnosis, or therapy of disease, or for the modifications of physiological function."

It should be differentiated from adverse event. An adverse event is any untoward medical occurrence that may present during treatment with a pharmaceutical product but which does not necessarily have a causal relationship with the medicinal product. $^{2}$

Although India accounts for around 10\% of global intake of medicines, the reporting of ADRs of medicines is a meagre $2 \%$ of the global occurrence. This is largely due to the poor reporting of adverse drug reactions in India. ${ }^{3}$ Despite this, India was $7^{\text {th }}$ in position amongst the top ten countries contributing to global drug safety database. ${ }^{4}$ Pharmacovigilance, as defined by the WHO, is the science and activities relating to the detection, assessment, understanding and prevention of adverse events or any other possible drug-related problems. ${ }^{5}$

Recently this definition has been extended to include herbal drugs, traditional and complementary and alternative medicines (CAM), blood products, biologicals, vaccines and even medical devices. In order to promote vigilance of adverse events in India, Central Drugs Standard Control Organization (CDSCO) initiated a nationwide pharmacovigilance programme in 2010. This programme is coordinated by the Indian Pharmacopoeia Commission (IPC), Ghaziabad. The process of pharmacovigilance is executed with the help of
DOI: 10.5530ijopp.10.1.7

Address for correspondence: Dr. Prashant Shukla, Department of Pharmacology, Government Medical College, Patiala, Punjab-147001, INDIA.

Phone no: 91-84272-58812 (Mobile); 0175-2220486 (Landline) E-mail: dr.prashant.shukla@ outlook.com 
ADRs monitoring centres (AMCs). Currently, there are around 150 AMCs operational throughout India. ${ }^{6}$

At present, the most common way through which various AMCs report the occurrence of ADRs or AEs is Spontaneous reporting structure. It is a voluntary type of reporting which can be done by healthcare professionals, nurses, pharmacists, patients and their relatives and marketing authorization holder. So far, this type of reporting has been the mainstay of various national and international drug safety evaluations. But, spontaneous reporting structure suffers from the serious problem of under-reporting which can be as high as $98 \%{ }^{2,7}$

\section{Impact of ADRs}

ADRs put additional financial burden on patients in particular and the healthcare system at large. The attributable financial burden of drug-related morbidity and mortality is around Rs. 690 (US \$15) per ADR. ${ }^{8}$

ADRs can have a detrimental impact on the quality of life (QoL) of patients as well. ${ }^{9}$

\section{OBJECTIVES}

The objective of the study was to assess the pattern of adverse drug reactions (ADRs) along with the severity and causality assessment of the ADRs in the local population.

\section{MATERIAL AND METHODS}

This was an observational and retrospective study. A total of 288 adverse drug reactions were reported from 175 patients of the outpatient and inpatient department of various clinical departments of Rajindra Hospital, Government Medical College, Patiala, Punjab. The ADRs were collected from a period of November 2015August 2016.

\section{Inclusion criteria}

All the patients from the outpatient or inpatient department having any adverse reaction(s) after the commencement of treatment were included in the study.

\section{Exclusion criteria}

Those patients admitted for accidental or intentional poisoning due to drugs were excluded from the study.

\section{ADR form collection}

The ADRs were collected and filled according to the "Suspected Adverse Drug Reaction Reporting Form (Indian Pharmacopoeia Commission)" version 1 and version $1.2 .^{10,11}$

\section{Causality assessment}

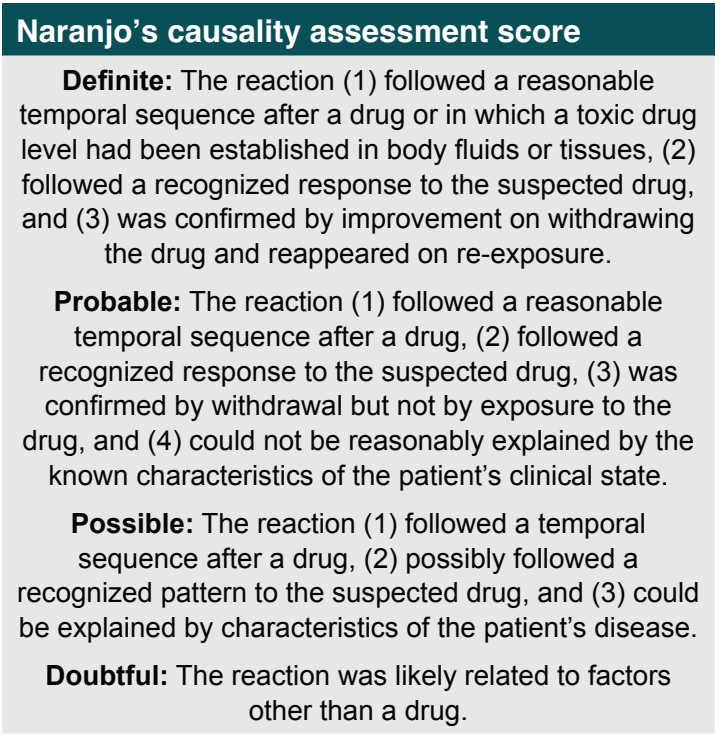

The causality assessment of the various adverse drug reactions to the implicated drug was done according to the Naranjo's causality assessment score. ${ }^{12}$

\section{Severity score}

The severity of the various reactions was noted as per the modified Hartwig and Siegel scale. ${ }^{13}$

Mild

Level 1: The ADR requires no change in treatment with the suspected drug.

Level 2: The ADR requires that the suspected drug be withheld, discontinued or otherwise changed. No antidote or other treatment is required, and there is no increase in length of stay.

\section{Moderate}

Level 3: The ADR requires that the suspected drug be withheld, discontinued or otherwise changed, and/ or an antidote or other treatment is required. There is no increase in length of stay.

Level 4 (a): Any level 3 ADR that increases length of stay by at least one day.

Level 4 (b): The ADR is the reason for admission.

Severe

Level 5: Any level 4 ADR that requires intensive medical care.

Level 6: The ADR causes permanent harm to the patient.

Level 7: The ADR either directly or indirectly leads to the death of the patient.

All the observations thus made were statistically analyzed using appropriate tests.

Indian Journal of Pharmacy Practice, Vol 10, Issue 1, Jan-Mar, 2017 


\section{RESULTS}

During the study period of November 2015- August 2016, a total of 288 adverse drug reactions were reported from 175 patients of the outpatient and inpatient department of various clinical departments of Rajindra Hospital, Government Medical College, Patiala, Punjab. The age of the patients ranged from 10 years to 90 years. Out of 175 patients, 10 were pre-adolescents ( $<19$ years) while 32 patients belonged to geriatric age group (i.e. $\geq 60$ years). The mean age of the patients was 43.14 ( \pm 2.27 ) years.

Gender distribution of the patients showed that there were $67(38.28 \%)$ female and $108(61.7 \%)$ male patients indicating male preponderance [Table 1].

Out of 288 ADRs, the majority of ADRs were related to the skin and appendages (26.04\%) closely followed by gastrointestinal disorders $(24.3 \%)$. Other affected systems include Central nervous system (12.15\%), respiratory system $(7.29 \%)$, cardiovascular system (6.94\%) and miscellaneous $(23.2 \%)$. The miscellaneous group includes cases of shivering, chills, fever, eye, musculoskeletal and genito-urinary tract [Figure 1].

Out of 175 patients who suffered ADRs, 132 recovered, 20 were recovering at the time of reporting, while 10 failed to recover from the adverse effects. There was 1 case of fatality although the causality assessment indicated the relationship between the ADR and suspected drug to be possible. The outcome was unknown in 12 patients [Table 1].

Using Naranjo's causality assessment scale, there were 9 definite, 131 probable, 136 possible and 12 doubtful/ unlikely causality of the ADR with the suspected offending drug. Using Hartwig and Siegel scale of severity of $\mathrm{ADR}$, it was found that there were 230 mild $(79.86 \%)$, 52 moderate $(18.05 \%)$ and 6 severe $(2.08 \%)$ ADRs. Dechallenge was done in 137 (78.28\%) patients. Out of 137 patients, ADRs abated in 93 (53.1\%) patients while in rest $44(25.14 \%)$ patients, ADRs did not abate at the time of reporting. Rechallenge was done in 87 (49.7\%) patients. Out of 87 patients, ADRs reappeared in $11(6.28 \%)$ patients while it did not appear in 76 $(43.42 \%)$ patients. Duration of ADRs was found be $\leq 1$ day in $54.2 \%$ of patients, between $1-5$ days in $18.28 \%$ of patients and $>5$ days in $5.7 \%$ of patients. While in $21.7 \%$ patients, ADRs were continuing at the time of reporting [Table 2].

Out of the various classes of drugs implicated to be responsible for adverse drug reactions, the most common drug class was that of anti- microbials (53.7\%) followed by IV fluids (11.42\%), analgesics (10.28\%), anti-ulcer drugs (5.14\%), anti-cancer drugs (4.5\%) and miscellaneous (14.96\%). Among anti-microbials, the various groups were antibiotics $(43.42 \%)$ and antivirals (10.28\%). Miscellaneous group included anti-epileptics, multi-vitamins, steroids, anti-allergic, anti- asthmatic, anti- coagulants, anti-psychotics and anti-hypertensive drugs [Figure 2].

As far as seriousness of the ADRs is concerned, it was non-serious in majority of the cases $(67.4 \%)$. While it was serious in the rest of the cases $(32.6 \%)$. The seriousness was indicated in of terms patients who underwent hospitalization (19.4\%), required intervention (14\%), suffered disability $(2.28 \%)$, and the fatal cases $(0.57 \%)$

\section{Table 1: Characteristics of patients}

$\begin{array}{ccc}\text { Parameters } & & \text { Percentage } \\ \text { Age } & <19 \text { years } & 5.7 \% \\ \text { Gender } & \text { 20-59 years } & 76 \% \\ & \geq 60 \text { years } & 18.28 \% \\ \text { Addiction } & \text { Male } & 62 \% \\ & \text { Female } & 38 \% \\ & \text { Alcohol + Smoking } & 3.4 \% \\ \text { Outcomes } & \text { Alcohol } & 6 \% \\ & \text { Smoking } & 5.1 \% \\ & \text { Opium } & 0.57 \% \\ & \text { Recovered } & 75.4 \% \\ & \text { Recovering } & 11.42 \% \\ & \text { Failed to recover } & 5.7 \% \\ & \text { Unknown } & 6.8 \% \\ & \text { Fatal } & 0.57 \%\end{array}$

\section{Table 2: Characteristics of ADRs}

Parameters

Seriousness

Non- serious
Serious
Death

Percentage of ADRs

Seriousness

Required intervention
Hospitalization
Disability

Life- threatening

Congenital anomaly

Severity

Mild

Moderate

Severe

Duration

$<1$ day

1-5 days

$\geq 5$ days

Causality

Certain/ Definite

Probable

Possible

Unlikely
$67.4 \%$

$32.6 \%$

$0.57 \%$

$14 \%$

$19.4 \%$

$2.28 \%$

$0 \%$

$0 \%$

$230(79.86 \%)$

$52(18.05 \%)$

$6(2.08 \%)$

$54.2 \%$

$18.28 \%$

$5.7 \%$

$3.1 \%$

$45.48 \%$

$47.22 \%$

$4.16 \%$ 


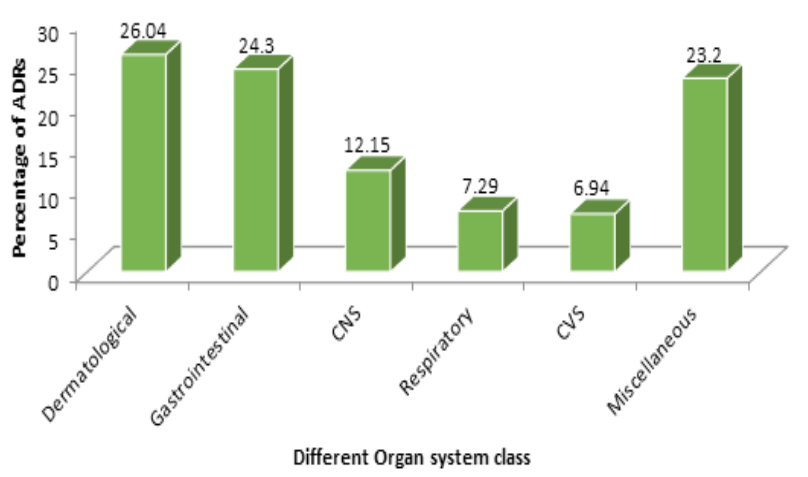

Figure1: Various organ system class affected.

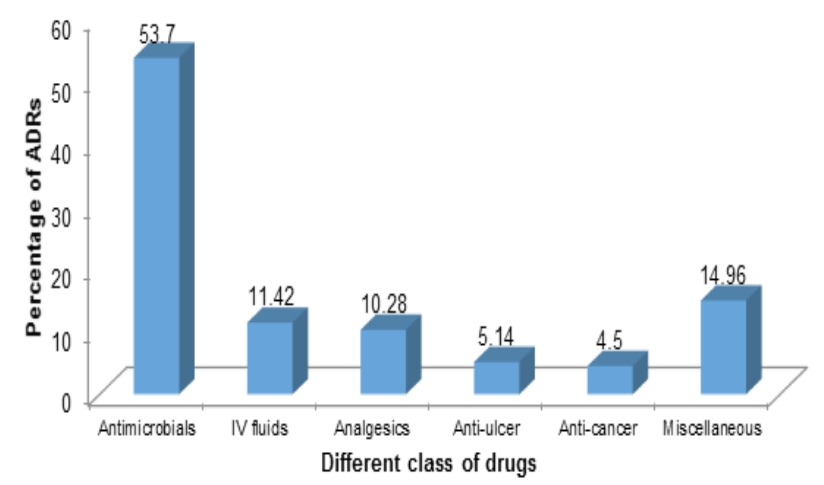

Figure 2: Various drug class implicated in the ADRs.

History of substance abuse was present in 27 (15.4\%) patients. Out of these, $11(6 \%)$ patients were alcoholic; $9(5.1 \%)$ patients were smokers; $6(3.4 \%)$ were both alcoholic and smokers; and $1(0.57 \%)$ patient was opium addict.

Although there was no predilection of ADRs to a product of any particular pharmaceutical company; but in $4.57 \%$ patients, the ADRs were suspected to be due to a particular product from a specific pharmaceutical company.

\section{DISCUSSION}

In the pharmacotherapy of various diseases, most of the drugs are likely to have a dual effect- beneficial as well as adverse. So, the best way to control these adverse effects is to have a triple pronged approach of prevention, treatment and rehabilitation.

In this retrospective study, a total of 288 ADRs were reported from 175 patients. The mean age of patients was $43.14( \pm 2.27)$ years. Majority of the patients $(76 \%)$ were in the age group 19-59 years. Gender distribution of the patients showed that there were $67(38.28 \%)$ female and 108 (61.7\%) male patients indicating male preponderance. A study conducted by Bhattacharjee $\mathrm{P}$ et al (2016) found similar results. The study reported that majority of the patients $(78.95 \%)$ were in the age group 12-59 years. And there was preponderance of ADRs in males as compared to females $(56.84 \%$ versus $43.16 \%) .{ }^{14}$

The study found that ADRs related to skin and appendages $(26.04 \%)$ were most common, closely followed by gastro-intestinal related disorder (24.3\%). Apart from skin and gastro-intestinal related disorders, Central nervous system $(12.15 \%)$, respiratory system $(7.29 \%)$, cardiovascular system $(6.94 \%)$ and miscellaneous $(23.2 \%)$ were also involved. The miscellaneous group included cases of shivering, chills, fever, eye, musculoskeletal and genito-urinary tract. A study conducted by Patidar D et al (2013) also reported dermatological ADRs to be the most frequent $(68.75 \%)$, followed by respiratory, central nervous system (9.37\% each), and gastrointestinal ADRs (6.25\%). ${ }^{15}$ Another study conducted by Agrawal $\mathrm{M}$ et al (2015) reported that the dermatological system $(65.38 \%)$ was the most affected organ system followed by gastro-intestinal related disorder $(26.92 \%) .{ }^{16}$

The present study found that the most common drug class was that of anti- microbials $(53.7 \%)$ followed by IV fluids (11.42\%), analgesics (10.28\%), anti-ulcer drugs $(5.14 \%)$, anti-cancer drugs $(4.5 \%)$ and miscellaneous $(14.96 \%)$. Among anti-microbials, the various groups were antibiotics $(43.42 \%)$ and antivirals (10.28\%). Miscellaneous group included anti-epileptics, multivitamins, steroids, anti-allergic, anti- asthmatic, anticoagulants, anti-psychotics and anti-hypertensive drugs. A study conducted by Patidar D et al (2013) reported that the drug class most commonly implicated with ADRs was antibiotics followed by anti-tubercular drugs, anti-gout drugs, NSAIDs and blood related products. ${ }^{15}$ Another study conducted by Roy K et al(2015) also found that the most common drug class implicated in ADRs was anti-microbials (32.67\%) followed by analge$\operatorname{sics}(24.49 \%) .{ }^{17}$

The study was fraught with a few limitations. First, ADRs were retrospectively collected by reviewing administrative medical records, which were not established for the purpose of research. Another limitation was that it was by large based on spontaneous reporting. Had it been an active surveillance, larger number of ADRs could have been documented. Furthermore, based on the data collected, preventability of the ADRs could not be ascertained. The short duration of the study, less number of ADRs and limited patient followup were other drawbacks of this study.

\section{CONCLUSION}

The pharmacovigilance program of India suffers from the problem of under-reporting. To curb this, wide- 
spread awareness programs targeting healthcare personnel at each and every level is warranted. Furthermore, the process of pharmacovigilance should be a continuous one so as to detect even the rare ADRs. It can also help in detecting batch- specific ADRs so that the particular batch of drugs could be withdrawn from the market in time.

\section{ACKNOWLEDGEMENT}

The author(s) are thankful to the students of Government Nursing College, Patiala, Punjab for their cooperation in ADR collection.

\section{CONFLICTING INTEREST}

The author(s) declared no potential conflicts of interest with respect to the research, authorship, and/or publication of this article.

\section{SOURCE OF FUNDING}

Nil

\section{ABBREVIATION USED}

Adverse Drug Reactions (ADRs), World Health Organization (WHO), Complementary and Alternative Medicines (CAM), Central Drugs Standard Control Organization (CDSCO), Indian Pharmacopoeia Commission (IPC), ADRs Monitoring Centres (AMCs), Adverse Events (AEs), United States (US), Intra Venous fluids (IV fluids)

\section{REFERENCES}

1. International drug monitoring: The role of National Centres. Report No: 498. Geneva, Switzerland: World Health Organization; World Health Organization; 1972.

2. Guidelines for detecting and reporting adverse drug reactions. Individual case safety reports for healthcare professionals. Rational Drug Use and Pharmacovigilance Department- JFDA. 2014: 6.
3. Bahri C. How India tackles adverse drug reactions - by ignoring data. IndiaSpend 2016 Feb 8. Available from: URL:http://www.indiaspend.com/ cover-story/how-india-tackles-adverse-drug-reactions-by-ignoring-data-45036

4. Lihite RJ, Lahkar M. An update on the Pharmacovigilance Programme of India.Frontiers in Pharmacology. 2015;6:194. https://doi.org/10.3389/ fphar.2015.00194 I PMid:26441651 PMCid:PMC4585088.

5. World Health Organization (WHO). The importance of pharmacovigilance: Safety monitoring of medicinal products. 2002.

6. Pharmacovigilance Programme of India (PvPI). National Coordination Centre. Indian Pharmacopoeia Commission 2013, Ghaziabad. [cited 2016 Sep 5]. Available from: URL: http://www.ipc.gov.in/PvPI/pv_about.html.

7. Fletcher AP. Spontaneous adverse drug reaction reporting vs event monitoring: a comparison. Journal of the Royal Society of Medicine. 1991;84(6):341-4. PMid:2061900 PMCid:PMC1293280.

8. Ramesh M, Pandit J, Parthasarathi G. Adverse drug reactions in a south Indian hospital- their severity and cost involved. Pharmacoepidemiology and Drug Safety. 2003;12(8):687-92. https://doi.org/10.1002/pds.871; PMid:14762985.

9. Rolfes L, Hunsel FV, Taxis K, Puijenbroek EV. The impact of experiencing Adverse Drug Reactions on the Patient's Quality of Life: A retrospective Crosssectional study in the Netherlands. Drug Saf. 2016:39(8):769-76. https://doi. org/10.1007/s40264-016-0422-0 ; PMid:27145946 PMCid:PMC4933735.

10. Suspected Adverse Reaction Reporting Form for VOLUNTARY reporting of Adverse Drug Reactions by healthcare professionals. National Coordinating Centre Pharmacovigilance Programme of India. India Pharmacopoeia Commission Ministry of Health \& Family Welfare Government of India. Available from: URL: http://www.ipc.gov.in/PvPI/ADRReportingForm.pdf.

11. Suspected Adverse Reaction Reporting Form For VOLUNTARY reporting of Adverse Drug Reactions by healthcare professionals (version 1.2). National Coordination Centre Pharmacovigilance Programme of India. Ministry of Health \& Family Welfare, Government of India. Available from: URL: http://ipc.nic.in/ writereaddata/mainlinkFile/File416.pdf.

12. Naranjo CA, Busto U, Sellers EM, Sandor P, Ruiz I, Roberts EA, et al. A method for estimating the probability of adverse drug reactions. Clin Pharmacol Ther. 1981;30:239-45. https://doi.org/10.1038/clpt.1981.154 ; PMid:7249508.

13. Hartwig SC, Siegel J, Schneider PJ. Preventability and severity assessment in reporting adverse drug reactions. Am J Hosp Pharm.1992;49(9):2229-32. PMid:1524068.

14. Bhattacharjee P, Das L, Ghosh R, Lalromawii, Das UK. Pattern of adverse drug reactions reported at a tertiary health care teaching hospital of Tripura: a retrospective study. Int J of Basic and Clin Pharmacol. 2016;5(4):1293-99. https://doi.org/10.18203/2319-2003.ijbcp20162177.

15. Patidar D, Rajput MS, Nirmal NP, Savitri W. Implementation and evaluation of adverse drug reaction monitoring system in a tertiary care teaching hospital in Mumbai, India. Interdisciplinary Toxicology. 2013;6(1):41-6. https://doi. org/10.2478/intox-2013-0008; PMid:24170978 PMCid:PMC3795320.

16. Agrawal M, Hishikar R, Joshi U, Halwai A, Toddar TL, Khubchandani V, et al. Adverse Drug Reaction Scenario at ADR Monitoring Centre of Tertiary Teaching Hospital at Raipur. Indian Journal of Pharmacy and Pharmacology. 2015;2(3):169-75.

17. Roy K, Divya S, Nadig P, Prakash B. Monitoring and analysis of adverse drug reactions in a private tertiary care teaching hospital. Asian J Pharm Clini Res. 2015;8(2):335-7. 